\title{
Membangun Kesadaran Bernegara di Sekolah Dasar
}

\author{
Dewi Restiaji ${ }^{1}$, Meiwatizal Trihastuti ${ }^{2}$, Yayuk Hidayah ${ }^{3}$, Lisa Retnasari $^{4}$ \\ ${ }^{1}$ SDN Jagir I/393, Surabaya \\ ${ }^{2}$ STKIP Pasundan Cimahi \\ ${ }^{3,4}$ Pendidikan Guru Sekolah Dasar, Universitas Ahmad Dahlan Yogyakarta \\ ²meiwatizal@yahoo.co.id \\ 33yayuk.hidayah@pgsd.uad.ac.id
}

\begin{abstract}
ABSTRAK
Tujuan dari penelitian ini adalah untuk mengetahui usaha membangun kesadaran bernegara di Sekolah Dasar. Metodologi penelitian menggunakan kualitatif deskriptif dengan subjek penelitian adalah siswa-siswi kelas VI C SDN Jagir I/393, Surabaya Tahun Ajaran 2019/2020. Pengambilan data menggunakan observasi, wawancara dan dokumentasi. Analisis data menggunakan Miles dan Huberman yaitu reduksi data, penyajian data dan penarikan kesimpulan. Hasil penelitian menunjukan bahwa implementasi pembelajaran membangun kesadaran bernegara Di SDN Jagir I/393, Surabaya dilakukan dalam perencanaan, pelaksanaan dan evaluasi. Faktor penghambat pembelajaran membangun kesadaran bernegara Di SDN Jagir I/393 Surabaya adalah penyiapan pembelajaran, kemampuan mengendalikan kelas dan lingkungan peserta didik. Faktor pendukung pembelajaran membangun kesadaran bernegara di SDN Jagir I/393 Surabaya adalah curah pendapat antar guru di di SDN Jagir I/393 Surabaya, penyediakan sarana belajar, dan kepemimpinan, kebijakan kepala sekolah.
\end{abstract}

Kata Kunci: Kesadaran Bernegara, Sekolah Dasar

\begin{abstract}
The purpose of this study is to investigate efforts to build state awareness in elementary schools. The research methodology uses descriptive qualitative research subjects are students of class VI C SDN Jagir I / 393, Surabaya Academic Year 2019/2020. Retrieval of data using observation, interviews, and documentation. Data analysis using Miles and Huberman is data reduction, data presentation, and conclusion drawing. The results showed that the implementation of learning to build state awareness At SDN Jagir I / 393, Surabaya was carried out in the planning, implementation, and evaluation. The inhibiting factors of learning to develop state awareness At SDN Jagir I / 393 Surabaya are the preparation of learning, the ability to control class, and the environment of students. The supporting factors of learning to build state awareness at SDN Jagir I / 393 Surabaya are brainstorming among teachers at SDN Jagir I / 393 Surabaya, providing learning facilities, and leadership, principal school policy.
\end{abstract}

Keywords: State Awareness, Elementary School

\section{PENDAHULUAN}

Penelitian ini berkenaan dengan upaya membangun kesadaran bernegara di Sekolah Dasar. Kesadaran bernegara pada jenjang Sekolah Dasar menarik untuk di lakukan sebagai tema kajian mengingat posisi strategis pada jenjang Sekolah Dasar bagi peserta didik. Sekolah Dasar adalah penyelenggara program pendidikan bagi anak-anak berusia 6-12 tahun (Suharjo, 2006). Dalam Undang-Undang Nomor 20 Tahun 2003 tentang sistem Pendidikan Nasional di jelaskan bahwa "jenjang pendidikan dasar dan menengah adalah jenis pendidikan formal untuk peserta didik usia 7 sampai 18 tahun dan merupakan persyaratan dasar bagi pendidikan yang lebih tinggi". Pendidikan adalah salah satu usaha sistematis dalam memberikan pembelajaran guna dalam mewujudkan manusia yang memiki kecerdasan yang bermanfaat bagi kehidupannya. Pendidikan ialah bagian dari kehidupan manusia sebagai usaha dalam memanusiakan manusia (Sudjana, 1987). Dalam Peraturan Menteri Pendidikan dan Kebudayaan Nomor 21 Tahun 2016 Tentang Isi Pendidikan Dasar dan Menengah terdapat 
beberapa kompetensi inti tingkat pendidikan dasar di antaranya pengetahuan dan keterampilan. Adapun cakupan dalam kompetensi pengetahuan adalah pemahaman faktual, dan cakupan dalam kompetensi keterampilan adalah keterampilan berfikir dan bertindak.

Kesadaran bernegara adalah sikap yang sesuai dengan kepribadian bangsa yang kemudian menjadi pengharapan dari cita-cita tujuan negara. Sebagai bangsa Indonesia suatu keniscayaan yang eksistensi dan perkembangan berlandaskan nilai kebangsaan yang sangat tinggi yakni Pancasila. Namun kenyataan di lapangan masih banyak fenomena di masyarakat yang tidak mencerminkan nilai kebangsaan, sehingga menimbulkan konflik sosial kultur. Oleh karena itu, perlu dikembangkan pendidikan nilai sebagai sarana pedagogis sosio-kultural yang sistematis untuk membangun karakter bangsa. Pasal 31 ayat 3 berbunyi "pemerintah mengusahakan, menyelenggarakan satu sistem pendidikan nasional yang meningkatkan keimanan, ketakwaan serta akhlak mulia dalam rangka mencerdaskan kehidupan bangsa yang diatur oleh undang-undang". Dengan kata lain warga negara Indonesia seharusnya mengembangkan diri menjadi individu yang cerdas pikiran, perasaan dan perilakunya dengan pendidikan yang tidak lepas dari kebudayaan yang mengantarkan menjadi manusia yang memiliki kesadaran bangsa (Winataputra \& Budimansyah., 2017)

Membangun kesadaran bernegara di Sekolah Dasar di rasa tepat, mengingat perkembangan siswa Sekolah Dasar umumnya berada dalam tahapan operasioal konkret. Pada taraf konkret, siswa hanya mampu memecahkan masalah yang di hadapinya secara langsung. Ia belum melihat adanya alternatif dalam memecahkan suatu masalah (Nasution.S., 1982). Membangun kesadaran bernegara di Sekolah Dasar adalah bagian dari peneguhan Pendidikan Karakter pada Sekolah Dasar. Pendidikan karakter pada sekolah dasar menjadi kesempatan strategis dalam membelajarkan siswa mengenai karakter (Hidayah, Suyitno, Retansari, \& Ulfah, 2018). Berdasarkan Permendikbud RI Nomor 57 Tahun 2014 mata pelajaran Pendidikan Pancasila Dan Kewarganegaraan merupakan kelompok mata pelajaran A yaitu mata pelajaran dengan tujuan untuk mengembangkan sikap, kompetensi pengetahuan peserta didik Sekolah Dasar. Pendidikan Pancasila dan Kewarganegaraan masuk dalam kelompok mata pelajaran A sesuai dengan tujuan pendidikan Kewarganegaraan yaitu sebagai mata pelajaran yang mempunyai visi untuk menyiapkan generasi penerus bangsa yang mempunyai kesadaran bernegara. Tujuan dari Pendidikan Kewarganegaraan merupakan proses untuk menyiapkan generasi yang mengetahui tanggung jawabnya sebagai warga negara (Winataputra \& Budimansyah, 2012). Fokus, isi, dan proses pendidikan dari civic education adalah proses dari pemahaman, penghayatan dari pelaksanaan cita-cita prinsip demokrasi konstitusional (Winataputra \& Budimansyah, 2012).

Penelitian terdahulu mengenai kesadaran bernegara di Sekolah Dasar yang telah dilakukan antara lain. Penelitian pengaruh program berbasis praktik kesadaran terhadap 64 anak-anak kelas dua dan tiga usia 7-9 tahun. Hasil penelitian menunjukan bahwa setelah program di laksanakan selama 30 menit, dua kali per minggu, selama 8 minggu para guru melaporkan bahwa terdapat perubahan perbaikan dalam perilaku anak. (Flook et al., 2010). Penelitian dalam pelaksanaan pendidikan karakter di Sekolah Dasar yang menekankan pada rujukan integratif (normatif, prosedural, dan kontekstual) menghasilkan bahwa rujukan normatif yang dipakai adalah agama (60\%), tujuan pendidikan nasional (25\%), budaya (10\%), dan Pancasila $(5 \%)$; kedua, rujukan prosedural praktik dalam bentuk doktrin (45\%), pembiasaan (37\%), keteladanan $(11 \%)$, pengembangan iklim suasana $(5 \%)$, pengembangan penalaran dan perasaan (4\%), dan partisipatif/kolaboratif (1\%); serta ketiga, rujukan kontekstual berupa pengondisian lingkungan sekolah (56\%), program khusus (24\%), kegiatan keluar sekolah (13\%), kerja sama orang tua (4\%), dan upaya preventif (3\%). (M.D. Niron, Budiningsih, \& Pujiriyanto, 2013).

Dunia pendidikan tidak hanya sekedar menunjukan pengetahuan moral, tetapi juga menyadarkan dan melakukan tindakan moral (Sudrajat, 2011). Penting kiranya pendidikan karakter dilakukan sejak dini, sehingga mampu mencetak insan yang tidak hanya paham definisi moral, namun juga menjadi manusia yang bermoral. Selain itu penelitian tentang integrasi nilai-nilai karakter bangsa pada kegiatan pembelajaran menunjukan bahwa integrasi nilai-nilai karakter bangsa dapat dilakukan pada mata pelajaran untuk menyiapkan peserta didik dalam pengaplikasian nilai karakter dalam kehidupan 
sehari-hari. Adapun tahap dalam kegiatan pembelajaran yakni pendahuluan, inti dan penutup. Setiap tahap pembelajaran, terdapat proses aktualisasi nilai-nilai karakter bangsa. Pihak sekolah, guru, dan orang tua bersinergi membentuk iklim yang mendukung sebagai pengejawantahan dari nilai karakter bangsa peserta didik dalam praktiknya (Anik, 2010)

Berdasarkan uraian tersebut, peneliti merasa terarik untuk melakukan penelitian dengan judul " Membangun Kesadaran Bernegara Di Sekolah Dasar". Rumusan masalah dalam penelitian ini adalah :

1) Bagaimana implementasi pembelajaran membangun kesadaran bernegara di SDN Jagir I/393 Surabaya?

2) Faktor apa saja yang mendukung dan menghambat pembelajaran membangun kesadaran bernegara di SDN Jagir I/393 Surabaya?

Adapun manfaat penelitian ini secara teoritis adalah mampu memberikan sumbangan pemikiran dalam mengembangkan keilmuan Pendidikan Kewarganegaraan ke-SDan. Sementara manfaat secara praktis adalah bagi guru DS, dapat menjadi dasar dalam memberikan pembelajaran membangun kesadaran bernegara di Sekolah Dasar dan memberikan gambaran bahwa pendidikan haruslah mampu mendukung usaha meningkatkan civic knowledge yang merupakan salah satu kompetensi warga negara dalam negara demokrasi.

\section{METODE PENELITIAN}

Penelitian ini menggunakan penelitian kualitatif dengan penyajian data berupa katakata. Bogdan dan Taylor menjelaskan bahwa penelitian kualitatif merupakan penelitian yang menghasilkan data secara deskriptif berdasarkan perilaku yang diamati (Moleong, 2000). Peneliti memiliki dua alasan mengapa penelitian ini dilakukan secara kualitatif. Pertama, kajian penelitian ini merupakan kajian tentang membangun kesadaran bernegara di Sekolah Dasar yang dalam penelitian ini mengandung unsur yang kontekstual. Kedua, berdasarkan latar belakang penelitian yang mengandung keterkaitan masalah yang dikaji, peneliti memerlukan adaptasi terhadap perubahan situasi yang terjadi di lapangan.

Lokasi penelitian di lakukan di lingkungan SDN Jagir I/393, Surabaya. Penelitian dilakukan selama bulan Juli 2019September 2019. Peneliti menggunakan purpose sampling dengan pertimbangan efisiensi informasi. Adapun subjek dalam penelitian ini adalah guru kelas VI C SDN Jagir I/393, dan siswa kelas VI C SDN Jagir I/393, Surabaya. Teknik pengumpulan data dilakukan dengan wawancara secara struktur, observasi dan dokumentasi. Tahap penelitian dilakukan dengan beberapa tahap yaitu, tahap pra penelitian meliputi persiapan yang dilakukan peneliti sebelum terjun ke lapangan. Tahap pelaksanaan meliputi mengumpulkan data dari responden sebagai subjek penelitian. Tahap penyusunan hasil penelitian, meliputi tahap menyusun hasil penelitian kemudian mempublikasikan dalam bentuk karya ilmiah yang di muat dalam jurnal nasional terindeks atau jurnal internasional yang bereputasi. Data yang diperoleh dari wawancara dan observasi disusun dalam bentuk catatan lapangan dengan didukung data dari dokumentasi kemudian sampai pada titik jenuh hingga tidak ada informasi yang baru.

Analisis data dalam penelitian ini menggunakan model dari Miles dan Huberman berupa reduksi data, penyajian data dan penarikan kesimpulan (Miles \& Huberman, 1992). Peneliti melakukan reduksi data dengan memfokuskan pada hasil penelitian yang di anggap penting yang meliputi proses pembelajaran membangun kesadaran bernegara di SDN Jagir I/393, Surabaya. Setelah mereduksi data kemudian peneliti melakukan penyajian data berupa mencari penyusunan data yang telah di analisis dalam bentuk paragraf. Selanjutnya setelah reduksi data dan penyajian data, peneliti melakukan penarikan kesimpulan dengan mencari kejelasan data yang telah dianalisis kemudian disusun dalam bentuk kesimpulan singkat mengenai membangun kesadaran bernegara di Sekolah Dasar.

\section{HASIL \& PEMBAHASAN}

\section{Implementasi Pembelajaran Membangun Kesadaran Bernegara di SDN Jagir I/393, Surabaya}

Implementasi pembelajaran kesadaran bernegara yang dilakukan di SDN Jagir I/393, Surabaya dalam pembelajaran adalah sebagai upaya dalam memupuk sikap dan perilaku yang berdasarkan nilai-nilai falsafah bangsa sejak dini. Implementasi pembelajaran kesadaran bernegara yang dilakukan di SDN Jagir I/393 dilakukan dalam strategi pembelajaran yang mencakup aspek 
perencanaan, pelaksanaan dan evaluasi. Dalam tahapan perencanaan, implementasi pembelajaran kesadaran bernegara yang dilakukan di SDN Jagir I/393 dilakukan secara eksplisit dalam rencana pembelajaran oleh guru. Dalam pelaksanaan pembelajaran, kesadaran bernegara yang dilakukan di SDN Jagir I/393 dilakukan melalui metode, media dan model pembelajaran dari guru sesuai dengan kurikulum 2013. Dalam evaluasi, pembelajaran kesadaran bernegara yang dilakukan di SDN Jagir I/393 adalah dengan memberikan penekanan pada aspek afektif dengan tetap mengemban prinsip-prinsp penilaian dalam kurikulum 2013 yaitu sahih, objektif, terpadu, adil, transparan, berksinambungan, edukatif, sistematis dan akuntabel.

Berdasarkan wawancara terhadap guru kelas VI C SDN Jagir I/393 Surabaya Tahun Ajaran 2019/2020, tahapan perencanaan implementasi pembelajaran kesadaran bernegara yang dilakukan di SDN Jagir I/393 Surabaya dilakukan secara sitematis yang dituangkan dalam penyusunan rencana pelaksanaan pembelajaran (RPP). Rencana pelaksanaan pembelajaran yang dibuat oleh guru dilengkapi dengan media dan lembar kerja siswa yang mengandung pembelajaran kesadaran bernegara sebagai upaya pengembangan nilai-nilai kesadaran bernegara yang meliputi persatuan dan kesatuan sebagai warga negara Republik Indonesia. Implementasi pembelajaran kesadaran bernegara yang dilakukan oleh guru didasari dengan kesadaran guru bahwa lingkungan sekolah merupakan bentuk sederhana dari kehidupan bernegara secara luas. Dalam pengimplementasian kesadaran berkonstitusi di lingkungan sekolah, sekolah diibaratkan seperti negara yang sama-sama memiliki peraturan. Peraturan dalam sekolah adalah tata tertib sekolah dan peraturan dalam negara adalah sesuai yang di atur dalam konstitusi (Darsono, 2016).

Melalui observasi yang peneliti lakukan, implementasi pembelajaran kesadaran bernegara yang dilakukan di kelas VI C SDN
Jagir I/393 Surabaya Tahun Ajaran 2019/2020 terdapat dua hal yang menjadi pokok dalam pencapaian indikator kesadaran bernegara bagi peserta didik. Yaitu penekanan pada sikap peserta didik dan pengenalan kesadaran sebagai warga negara. Indikator sikap peserta didik yang dirumuskan melalui pengembangan keterampilan sikap dengan berlandaskan pada Pancasila dan UndangUndang Dasar 1945. Sesuai dengan kajian yang dilakukan oleh Wahyuni, Setyosari, \& Kuswandi ( 2016) yang menghasilkan kesimpulan bahwa pembelajaran dengan kolaborasi tema dan konsep berguna agar anak mudah memahami berdasarkan satu tema yang berisi beberapa mata pelajaran. Dalam implementasi pembelajaran kesadaran bernegara kelas VI C SDN Jagir I/393, Surabaya guru melakukan pengenalan dan pengkondisian pembelajaran dengan menerapkan nilai-nilai Pancaila berupa ketuhanan, persatuan, keadilan. Lebih detail dalam pembelajaran tematik yang diakukan guru, guru memberikan konsep yang sesuai dengan tema agar peserta didik mudah dalam memahami.

Upaya penekanan sikap peserta didik terhadap kebermaknaan bernegara menjadikan guru melakukan melakukan internalisasi nilainilai Pancasila dalam setiap langkah pembelajaran. Dalam kajian Pendidikan Kewarganegaaraan, upaya internalisasi nilainilai Pancasila merupakan bagian dari misi Pendidikan Kewarganegaaraan yang tertuang dalam Permendiknas No.22 Tahun 2006 tentang standar Isi Pendidikan Nasional, yaitu bahwa Pendidikan Kewarganegaaraan merupakan mata pelajaran yang memfokuskan pada pembentukan warga negara yang memahami dan mampu melaksanakan hak-hak dan kewajibannya untuk menjadi warga negara Indonesia yang cerdas, terampil dan berkarakter yang diamanatkan oleh Pancasila dan UUD 1945. Guru kelas VI C SDN Jagir I/393 Surabaya menciptakan susana pembelajaran kesadaran bernegara dengan penekanan pada sikap peserta didik dapat teridentifikasi dalam tabel 1 berikut ini :

Tabel 1

Identifikasi pembelajaran kesadaran bernegara dengan penekanan pada sikap peserta didik kelas VI C SDN Jagir I/393 Surabaya

\begin{tabular}{llllll}
\hline No & Aktivitas Guru & Aktivitas siswa & Keterangan \\
\hline 1. & $\begin{array}{l}\text { Guru memberikan } \\
\text { mengenai persatuan }\end{array}$ & pemahaman & konsep & $\begin{array}{l}\text { Peserta didik } \\
\text { memahami dan melajar }\end{array}$ & $\begin{array}{l}\text { Pembagian kempok } \\
\text { dalam pembelajaran }\end{array}$ \\
\hline
\end{tabular}


nilai-nilai persatuan melalui

teman sebaya

2 Guru memberikan pemahaman konsep mengenai kesatuan
Peserta didik belajar memahami dan menerapkan nilai-nilai kesatuan melalui pengkondisian kelas dengan

mengedepankan pada komunikasi dua arah

3 Guru memberikan pemahaman konsep bernegara dengan mengaitkan beberapa konsep dalam mata pelajaran
Peserta didik mengikuti

pembelajaran
Penerapan pembelajaran model kooperatif

Penerapan pembelajaran model terpadu

\begin{tabular}{llllll}
\hline 4 & $\begin{array}{l}\text { Guru memberikan pemahaman konsep Peserta didik mengalami } \\
\text { dengan mengajak } \\
\text { mengekplorasi penemuan baru }\end{array}$ & $\begin{array}{l}\text { Penerapan pembelajaran } \\
\text { model } \\
\text { makna bernegara } \\
\text { terbimbing }\end{array}$ \\
\hline 5 & $\begin{array}{l}\text { Guru memberikan pemahaman konsep } \\
\text { secara deduktif }\end{array}$ & $\begin{array}{l}\text { Peserta didik mengalami } \\
\text { makna bernegara }\end{array}$ & $\begin{array}{l}\text { Penerapan pembelajaran } \\
\text { model langsung }\end{array}$ \\
\hline
\end{tabular}

\section{Sumber: Data diolah peneliti melalui wawancara, observasi dan dokumentasi}

Indikator kedua pengenalan kesadaran sebagai warga negara, guru mengembangkan dari peran siswa sebagai warga negara. Tujuan Pendidikan Kewarganegaaraan adalah mendidik siswa untuk menjadi warga negara yang baik, bertanggung jawab dan berpartisipasi dalam kehidupan demokratis (Maftuh, 2008). Upaya guru kelas VI C SDN Jagir I/393 Surabaya dalam pengenalan kesadaran sebagai warga negara kepada peserta didik merupakan bagian dalam menyiapkan warga negara yang memiliki nilainilai serta memiliki sejumlah kompetensi kewarganegaraan sehingga bermanfaat bagi negara. Pengenalan kesadaran sebagai warga negara Indonesia dimulai dengan memperhatikan kebutuhan strategi pembelajaran yang tepat bagi usia kelas VI Sekolah Dasar. Masitoh (2009) telah menjelaskan beberapa karakteristik cara belajar pada usia dini yaitu 1) melalui bermain, 2) membangun pengetahuan, 3) belajar secara alamiah, 4) pengembangan menarik, fungsional dan bermakna.

Berdasarkan wawancara dan observasi yang peneliti lakukan di kelas VI C SDN Jagir I/393 Surabaya dalam upaya pembelajaran kesadaran bernegara guru terlebih dahulu memberikan upaya penokohan terhadap peserta didik. Sebagaimana kutipan wawancara berikut ini,

“... dengan upaya penokohan peserta didik akan mulai tahu mengenai posisi yang ada dalam pemerintahan, misalnya saya melakukan pengenalan terhadap presiden, RT, Lurah..." (DR, 2019).

Guru di kelas VI C SDN Jagir I/393 Surabaya mempunyai misi untuk membangun character building Indonesia. Guru mengenalkan kepada siswa bahwa mereka merupakan bagian dari warga negara Indonesia dan akan menjadi calon penerus bangsa. Pendidikan Kewarganegaraan mempunyai tujuan dalam membangun character building Indonesia yang mencakup 1) kecakapan partisipatif, bertanggung jawab dalam berbangsa, 2) warga negara yang cerdas, kritis, demokratis, 3) mengembangkan kultur demokrasi yang berkeadaban, kebebasan, persamaan, toleransi dan tanggung jawab (A. Ubaedillah, 2015). Kesadaran sebagai warga negara juga diimbangi dengan kehidupan yang penuh dengan perbedaan. Guru di kelas VI C SDN Jagir I/393 Surabaya membelajarkan toleransi dan tanggung jawab kepada peserta didik melalui ethic berupa sopan santun agar terbentuk sikap yang positif pada diri anak. Guru di kelas VI C SDN Jagir I/393 Surabaya mewacanakan kebhinekaan sebagai hakikat dari realitas bahwa bangsa Indonesia adalah bangsa yang kaya akan perbedaan. Adapun alur pembelajaran pengenalan kesadaran sebagai warga negara ada dalam gambar 1 berikut ini: 


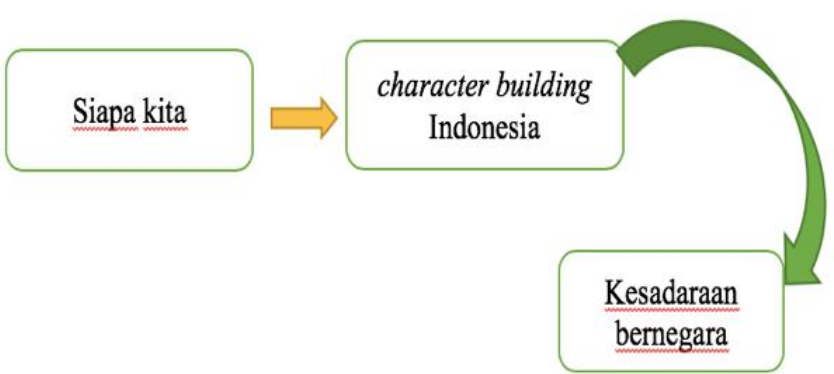

Gambar 1: Pembelajaran pengenalan kesadaran sebagai warga negara

Dari gambar 1, dapat di pahami bahwa guru terlebih dahulu memberikan pengertian mengenai kebermaknaan "siapa kita?". Dalam tahapan ini guru di kelas VI C SDN Jagir I/393, Surabaya menjelaskan bahwa yang dimaksud dengan "kita" adalah sebagai warga negara. Setelah peserta didik mengetahui lalu guru memberikan berbagai karakter keIindoesiaan yang menjadi bagian dari identitas Indonesia. Selanjutnya peserta didik di kelas VI C SDN Jagir I/393 memiliki seperangkat bekal dalam kesadaran bernegara. Peserta didik Sekolah Dasar merupakan bagian dari kelompok usia remaja yang merupakan social capital Indonesia (Nurhadianto, 2014), dengan demikian kesadaran bernegara sejak peserta didik Sekolah Dasar merupakan bagian dari mewujudkan manusia Indonesia yang seutuhnya. Dalam kajian yang menekankan pada nasionalisme dalam kesadaran bernegara dan berbudaya, disimpulkan bahwa dalam kehidupan bernegara, keselarasan kesadaran bernegara dan berbudaya merupakan hal yang penting (Nugraha, 2018) dalam pembangunan karakter bernegara dengan melibatkan budaya lokal. Penelitian di Kota Gorontalo menghasilkan bahwa budaya Hayula mengandung nilai luhur Pancasila yang bermanfaat bagi pembangunan karakter bangsa (Yunus, 2013).

\section{Faktor Pendukung dan Penghambat Pembelajaran Membangun Kesadaran Bernegara Di SDN Jagir I/393, Surabaya.} Implementasi pembelajaran membangun kesadaran bernegara di SDN Jagir I/393 Surabaya tidak telepas dari berbagai tantangan dan hambatan. Berdasarkan wawancara terhadap guru kelas VI C SDN

\section{KESIMPULAN \& SARAN}

Berdasarkan hasil dan pembahasan, kesimpulan dalam penelitian ini adalah : 1) Implementasi pembelajaran membangun kesadaran bernegara di SDN Jagir I/393 Surabaya dilakukan secara sistematis dalam
Jagir I/393 Surabaya, hambatan dalam upaya membangun kesadaran bernegara adalah persiapan kebutuhan yang relatif lama. Kemampuan guru dalam mengendalikan semangat peserta didik dan pengaruh lingkungan peserta didik yang kurang mendukung dalam upaya membangun kesadaran bernegara.

“... hambatan yang menjadi tantangan dalam membangun kesadaran bernegara bagi saya adalah mengendalikan kelas dan persiapan pembelajaran yang relatif lama. Namun demikian hal ini tidak menjadikan pengimplementasian membangun kesadaran bernegara menjadi terhambat karena kami selalui meminimalisir hambatan tersebut..." (DR,2019)

Berdasarkan hasil wawancara, guru telah memiliki upaya dalam meminimalisir hambatan pembelajaran membangun kesadaran bernegara. Guru mengupayakan agar pembelajaran membangun kesadaran bernegara tetap konstan dan sesuai dengan hasil belajar yang diinginkan. Setelah mengetahui tantangan atau penghambat dalam upaya pembelajaran membangun kesadaran bernegara beberapa cara yang digunakan dalam mengatasi permasalahan tersebut antara lain guru kelas VI C SDN Jagir I/393 Surabaya mengadakan curah pendapat dengan antar guru mengenai hambatan upaya pembelajaran membangun kesadaran bernegara. Menyediakan sarana yang mendukung pembelajaran dan kepemimpinan serta kebijakan kepala sekolah dalam upaya pembelajaran membangun kesadaran bernegara.

rencana pembelajaran yang mencakup perencanaan, pelaksanaan dan evaluasi. 2) Faktor penghambat pembelajaran membangun kesadaran bernegara di SDN Jagir I/393 Surabaya adalah kebutuhan persiapan pembelajaran yang relatif lama, kemampuan 
guru dalam mengendalikan semangat peserta didik dan pengaruh lingkungan peserta didik. Sementara itu faktor pendukung pembelajaran membangun kesadaran bernegara di SDN Jagir I/393 Surabaya adalah curah pendapat antar guru, menyediakan sarana yang mendukung pembelajaran, kepemimpinan serta kebijakan kepala sekolah.

\section{Ucapan Terimakasih}

Peneliti mengucapkan terimakasih kepada SDN Jagir I/393 Surabaya yang telah memberikan kesempatan pada peneliti untuk melaksanakan penelitian ini hingga selesai. Terimakasih kepada narasumber yang telah bersedia di wawancarai.

\section{DAFTAR PUSTAKA}

A. Ubaedillah. (2015). Pendidikan Kewarganegaraan Pancasila demokrasi dan korupsi. Jakarta: Media Group.

Anik, G. (2010). Integrasi Nilai-Nilai Karakter Bangsa Pada Kegiatan Pembelajaran. Cakrawala Pendidikan Edisi Khusus Dies Natalis UNY Th. XXIX.

Darsono, B. (2016). Menumbuhkan kesadaran berkonstitusi di lingkungan sekolah melalui pendidikan kewarganegaraan. HARMONY, 1(1), 14-29.

Flook, L., Smalley, S. L., Kitil, M. J., Galla, B. M., Kaiser-Greenland, S., Locke, J., ... Kasari, C. (2010). Effects of Mindful Awareness Practices on Executive Functions in Elementary School Children. Journal of Applied School Psychology, 26(1), 70-95. https://doi.org/10.1080/153779009033791 25

Hidayah, Y., Suyitno, Retansari, L., \& Ulfah, N. (2018). Jurnal Iqra': Kajian Ilmu Pendidikan. Jurnal Iqra': Kajian Ilmu Pendidikan, 3(2), 329-344.

M.D. Niron, C. A., Budiningsih, \& Pujiriyanto. (2013). RUJUKAN INTEGRATIF DALAM PELAKSANAAN PENDIDIKAN KARAKTER DI SEKOLAH DASAR. JURNAL KEPENDIDIKAN, 43(1), 19-31.

Maftuh, B. (2008). Internalisasi Nilai-Nilai Pancasila dan Nasionalisme Melalui Pendidikan Kewarganegaraan. EDUCATIONIST, II(2).

Masitoh, D. (2009). Strategi Pembelajaran TK. Surakarta: Universitas Terbuka.

Miles, B. M., \& Huberman, M. (1992). Analisis Data Kualitatif Buku Sumber
Tentang Metode-metode Baru. Jakarta: UIP.

Moleong, J. . (2000). Metode Penelitian Kualitatif. Bandung: PT. Remaja Rosdakarya.

Nasution.S. (1982). Berbagai Pendekatan dalam proses Belajar - mengajar. Jakarta: Bumi Aksara.

Nugraha, G. (2018). MENJADI PANCASILA : MEMBANGUN INDONESIA (Nasionalisme dalam Kesadaran Bernegara dan Berbudaya). In Prosiding Seminar Nasional PPKn 2018 "Seminar Nasional Penguatan Nilai-Nilai Kebangsaan Melalui Pendidikan Kewarganegaraan Persekolahan dan Kemasyarakatan" Laboratorium PPKn FKIP UNS, 7 Juli 2018 (pp. 1-14). Surakarta: Laboratorium PPKn FKIP UNS.

Nurhadianto. (2014). INTERNALISASI NILAI-NILAI PANCASILA DALAM UPAYA MEMBENTUK PELAJAR ANTI NARKOBA Nurhadianto,. Jurnal Pendidikan Ilmu Sosial, 23(2), 44-54.

Sudjana, N. (1987). Dasar-Dasar Proses Belajar Mengajar. Bandung: Sinar Baru Offset.

Sudrajat, A. (2011). Mengapa Pendidikan Karakter. Yogyakarta: FIS UNY.

Suharjo. (2006). Mengenal Pendidikan Sekolah Dasar Teori dan Praktek. Jakarta: Departemen Pendidikan Nasional Direktorat Jendral Pendidikan Tinggi Direktorat Ketenagaan..

Wahyuni, H. T., Setyosari, P., \& Kuswandi, D. (2016).

IMPLEMENTASI PEMBELAJARAN TEMATIK KELAS 1 SD. || Edcomtech, 1(2), 129-136.

Winataputra, U. ., \& Budimansyah, D. (2012). Pendidikan Kewarganegaraan Dalam Perspektif Pendidikan Untuk Mencerdaskan Kehidupan Bangsa: Gagasan, Instrumentasi, dan Praksis. Bandung: Widya Aksara Press.

Winataputra, U. S., \& Budimansyah., D. (2017). Civic Education, Konteks, Landasan, Bahan Ajar dan Kultur Kelas. Bandung: UPI.

Yunus, R. (2013). TRANSFORMASI NILAINILAI BUDAYA LOKAL SEBAGAI UPAYA PEMBANGUNAN

KARAKTER BANGSA (Penelitian Studi Kasus Budaya Huyula di Kota Gorontalo). Jurnal Penelitian Pendidikan, 14(1), 65-77. 